\title{
Upper intestinal bacterial flora during transpyloric feeding
}

\author{
H D DELlagRAMMATICAS, B I DUERDEN, AND R D G MILNER
}

Department of Paediatrics and Department of Medical Microbiology, University of Sheffield, Children's Hospital, Sheffield

SUMmARY Samples from the pharynx, stomach, duodenum or jejunum, and faeces were collected on 7 days between 1st and 28th day from neonates weighing less than $1.5 \mathrm{~kg}$ at birth who were fed by transpyloric tube. These were cultured on selective and non-selective media, and the results were expressed in a semi-quantitative manner. The number of bacterial species and the density of their growth increased with the patient's age; this was particularly noticeable with Gram-negative bacteria and the ratio of Gram-negative to Gram-positive organisms increased steadily in specimens from all sites with increasing age. The upper small intestine was more heavily colonised than the stomach early in life and the microflora present was predominantly faecal in nature. The species isolated from all sites were mainly aerobes or facultative anaerobes; strict anaerobes did not form a significant proportion of the microflora in these infants. Necrotising enterocolitis developed only after heavy jejunal colonisation with Gram-negative bacilli.

Since its introduction in $1970,{ }^{1}$ transpyloric feeding has become an established alternative to gastric feeding for neonates. Challacombe, Richardson, and Anderson ${ }^{2}$ used a polyethylene nasojejunal tube in infants without gastrointestinal disease and found that prolonged intubation of the upper small intestine resulted in qualitative changes in the microflora, and in particular in a significant increase in the number of coliforms present.

The purpose of the present study was to examine the bacterial flora of the upper small intestine qualitatively and semi-quantitatively in ill neonates of very low birthweight who were fed transpylorically, to compare this with their pharyngeal, gastric, and faecal flora, and to compare the results with the clinical condition of the patient. Particular attention was paid to necrotising enterocolitis, which has been reported to be more common with this method of feeding. ${ }^{3-5}$

\section{Materials and methods}

Subjects. All 19 ill neonates with birthweights $<1500 \mathrm{~g}$ who were admitted to the intensive care unit of the Jessop Hospital for Women between November 1980 and April 1981 and in whom transpyloric feeds were started within 12 hours of birth were included in the study. All infants received systemic antibiotic therapy; other clinical details are given in Table 1. The study did not interfere with the routine clinical care of the babies, as it was standard practice for very low birthweight infants to be fed transpylorically.

Feeds. All babies mainly received a humanised formula (Cow and Gate Premium Milk). Some babies were also offered feeds of pooled heatsterilised expressed breast milk, but for the purposes of the study they were regarded as being artificially fed.

The milk was given via a Silicon nasojejunal tube FG-5 (Vygon Ltd) as a continuous infusion controlled by a syringe pump. The syringes containing the milk were disposable and were changed every 4 hours. The nasojejunal tubes were inserted within approximately 30-40 minutes ${ }^{6}$ and were changed routinely every 4 days. The timing of insertion was determined by the clinician. The position of the tip of each nasojejunal tube was checked radiologically if a radiograph was indicated for other reasons, or by $\mathrm{pH}$ determination and the presence of bile in the aspirate. An orogastric tube was passed at the same time.

Bacteriological samples. Sets of four samples were collected from each baby: (1) pharyngeal swab/ secretions; (2) gastric aspirate; (3) duodenal/jejunal aspirate; (4) rectal swab/meconium/faeces. This set 
Table 1 Clinical characteristics of the study group

\begin{tabular}{|c|c|c|c|c|c|}
\hline Gender & $\begin{array}{l}\text { Birthweight* } \\
(g)\end{array}$ & $\begin{array}{l}\text { Gestational } \\
\text { age } \dagger(\text { weeks) }\end{array}$ & Diagnoses & $I P P V$ & $\begin{array}{l}\text { Outcome } \\
\text { (study period) }\end{array}$ \\
\hline $\mathbf{M}$ & 640 & 26 & RDS, apnoeic attacks, NEC, jaundice & YES & Survived \\
\hline $\mathbf{M}$ & 800 & 28 & RDS, ABO isoism (E-T), acute renal failure & YES & Died \\
\hline $\mathbf{M}$ & 840 & 28 & PROM, NEC & YES & Died \\
\hline $\mathbf{M}$ & 850 & 26 & PROM, $S$. albus septicaemia, meconium ileus & YES & Died \\
\hline $\mathbf{M}$ & 940 & 27 & RDS, jaundice, IVH & YES & Died \\
\hline $\mathbf{M}$ & 980 & 27 & RDS, IVH & YES & Died \\
\hline $\mathbf{M}$ & 1100 & 33 & Apnoeic attacks, $S$. albus septicaemia & NO & Survived \\
\hline $\mathbf{M}$ & 1120 & 28 & RDS, pneumonia, NEC & YES & Died \\
\hline $\mathbf{M}$ & 1160 & 28 & RDS, pulmonary haemorrhage, jaundice & YES & Survived \\
\hline $\mathbf{M}$ & 1180 & 28 & RDS, $E$. coli septicaemia, IVH & YES & Died \\
\hline $\mathbf{M}$ & 1200 & 28 & RDS, pneumothorax, apnoeic attacks, PDA, jaundice & YES & Survived \\
\hline $\mathbf{F}$ & 1220 & 29 & RDS, E. coli septicaemia, jaundice & YES & Survived \\
\hline $\mathbf{F}$ & 1220 & 29 & NEC & NO & Survived \\
\hline F & 1280 & 29 & PROM, apnoeic attacks & YES & Survived \\
\hline $\mathbf{M}$ & 1280 & 30 & Congenital pneumonia; jaundice, small IVH & NO & Survived \\
\hline $\mathbf{M}$ & 1320 & 29 & RDS, pneumothorax, NEC, jaundice, PDA & YES & Survived \\
\hline $\mathbf{M}$ & 1340 & 30 & Apnoeic attacks, $S$. albus septicaemia, PDA, small IVH & YES & Survived \\
\hline F & 1380 & 30 & RDS, NEC, jaundice & YES & Survived \\
\hline M & 1480 & 32 & Apnoeic attacks, $S$. aureus septicaemia, jaundice & YES & Survived \\
\hline
\end{tabular}

RDS = respiratory distress syndrome, NEC = necrotising entercolitis, $\mathbf{P R O M}=$ prolonged rupture of membranes, IVH $=$ intraventricular haemorrhage, $\mathrm{PDA}=$ patent ductus arteriosus, $\mathrm{E}-\mathrm{T}=$ exchange transfusion.

*Mean birthweight $1123(640-1480) \mathrm{g}$, tmean gestational age $28 \cdot 6(26-33)$ weeks.

of samples was collected on days $1,2,3,7,14,21$, and 28 of life between 0900 and 1100 hours. The first set of samples was obtained before giving the first milk feed.

In order to reduce contamination of gastric and duodenal or jejunal samples with organisms proliferating within the lumen of the tube, two initial aspirates, each equal to the tube volume, were discarded from each tube on each sampling day. The samples were taken to the laboratory for culture within 10 minutes of collection. Stuart's transport medium with charcoal was used for pharyngeal and rectal swabs but not for aspirates or faeces.

Laboratory procedure. Each sample was seeded on to a variety of non-selective and selective media for the semi-quantitative recovery and identification both of commensal organisms and potential pathogens. ${ }^{7}$ The media were blood agar, MacConkey's agar, Mitis-Salivarius agar, and Sabouraud's agar incubated aerobically; heated (Chocolate) blood agar incubated in air plus $\mathrm{CO}_{2}$; $\mathrm{BM}$-kanamycinvancomycin agar, reinforced-clostridial cotton blue agar, and Rogosa agar incubated anaerobically. The swab or a loopful of the aspirate was seeded on to a sector of each plate and a sterile loop was used to streak the specimen over the plate in a standard manner. The density of growth was scored on a scale $0-5+$ according to the extent of growth of each species around the streaks. The method was developed and evaluated in this laboratory for the semi-quantitative study of the bacterial flora of neonates. ${ }^{7}$ Growth was assessed after incubation for 24 and 72 hours. All strains isolated were purified and identified by standard conventional bacteriological methods.

Thirty-two random milk samples were also examined. Each was collected at the end of a 4-hour cycle, just before the syringe was due to be changed. They were cultured and assessed in the same manner.

\section{Results}

Twelve $(63 \%)$ of the 19 neonates survived the study period. Sixteen $(84 \%)$ neonates were ventilated and all received at least one course of antibiotics. Six $(31 \%)$ neonates developed necrotising enterocolitis, 2 of whom died. Eight neonates completed the full 7 sampling days. Altogether 372 bacteriological samples were collected. Details of the organisms isolated are shown in Table 2.

The pattern of colonisation of the four sites was essentially the same. The number of different species isolated increased from all four sampling sites with increasing age as also did the density of growth. This was particularly pronounced for Gram-negative organisms. Moreover the ratio of the number of Gram-negative strains isolated to the number of Gram-positive isolates rose progressively from $\mathbf{0 . 2}$ to 1.25 as the samples were collected from the pharynx through to the colon and as age increased; lower scores were obtained on days 1-3 and higher scores on days 7-28 (Table 3). About half the specimens collected on day $1(54 \%)$ and day $2(40 \%)$ were sterile, but only $8 \%$ of those collected on days 7-28 were sterile; all the later sterile specimens were from the stomach or small intestine. If growth occurred, most of the semiquantitative scores for specimens collected on days 


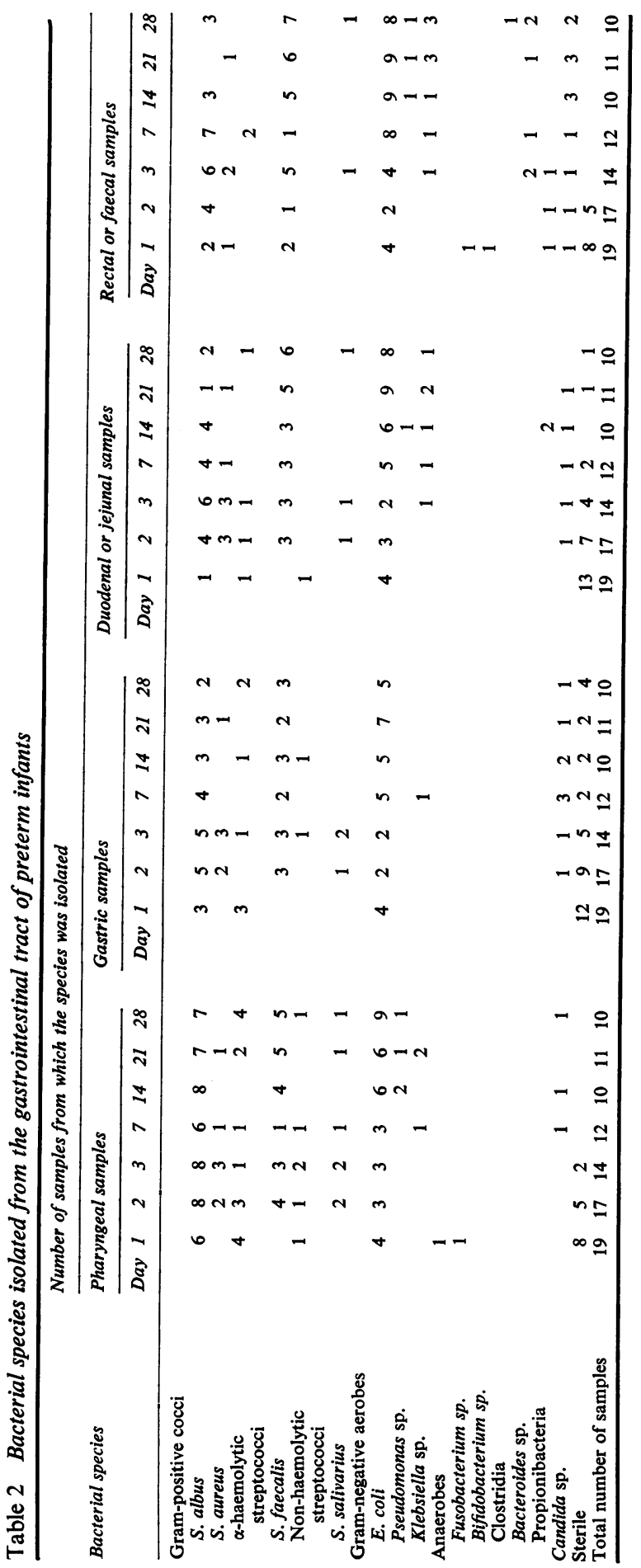


Table 3 Ratios of Gram-negative to Gram-positive organisms isolated from the four sampling sites during the 7 sampling days

\begin{tabular}{llclc}
\hline Days & Pharyngeal swabs & Gastric aspirate & Duodenal or jejunal aspirate & Rectal swab or faeces \\
\hline $1,2,3$ & $10 / 50(0 \cdot 2)$ & $8 / 32(0 \cdot 25)$ & $10 / 29(0 \cdot 34)$ & $11 / 24(0 \cdot 45)$ \\
$7,14,21,28$ & $31 / 57(0 \cdot 54)$ & $23 / 27(0 \cdot 85)$ & $34 / 32(1 \cdot 06)$ & $45 / 36(1 \cdot 25)$ \\
\hline
\end{tabular}

1-3 were in the range $1-3+$ and fewer than $10 \%$ of scores were $4-5+$. In specimens collected on days 7-28 many more scores were in the range 3-5+; this was particularly noticeable for the pharyngeal and faecal specimens and for colonisation with Escherichia coli.

In particular, after the first day the upper intestine (duodenum or jejunum) of the babies was more heavily colonised with organisms than the stomach. This flora was predominantly of 'faecal type' and comprised Streptococcus faecalis and $E$. coli with other coliform organisms occasionally. Few anaerobic organisms were isolated; most were from the faeces. No anaerobes were isolated from the duodenal or jejunal aspirates of the babies who developed necrotising enterocolitis.

Three babies showed a different, 'abnormal', pattern of bacterial colonisation. All four sampling sites were heavily colonised with $E$. coli from the first day and all 3 babies died, 2 of necrotising enterocolitis and 1 of E. coli septicaemia. Prolonged rupture of the membranes had been present in only one of them.

The bacteriological findings in the babies who developed necrotising enterocolitis were not appreciably different from those in the remainder of the group. However, no baby developed necrotising enterocolitis before jejunal colonisation with Gramnegative bacilli (coliforms). The 2 babies who died developed necrotising enterocolitis within the first 3 days of life and they were 2 of the 3 neonates heavily colonised by E. coli from day 1 .

Of the 32 milk samples $21(66 \%)$ were sterile, 9 $(28 \%)$ were lightly contaminated with Staphylococcus albus, and $2(6 \%)$ were moderately or heavily $(2+$ to $5+)$ contaminated with a Klebsiella sp. and E. coli. It was concluded that the milk did not contribute significantly to the colonisation of the upper intestine with Gram-negative organisms.

\section{Discussion}

The gastrointestinal tract at birth is thought to be either sterile or to harbour few organisms. However, within a few days the mouth and the colon acquire a profuse bacterial flora. The upper intestine of the normal infant is either sterile or contains a sparse, mainly Gram-positive flora. ${ }^{8}$ Challacombe, Richardson, and Anderson ${ }^{2}$ demonstrated that the presence of a polyethylene tube alters the flora of the upper gut. The present study is the first to attempt a longitudinal investigation throughout the first 4 weeks of life of the upper gut flora specifically in the very small, ill, preterm infant fed transpylorically through a Silicon tube.

Our results show that the upper gut of these babies becomes colonised with a 'faecal type' of flora, in which $S$. faecalis and Gram-negative bacteria predominate. This type of flora must arise either by ingestion or by retrograde spread and is similar to that found in cases of chronic diarrhoea, when normal intestinal motility is deranged and gastric acidity reduced. ${ }^{9}$

The bacterial flora isolated from specimens aspirated through long nasojejunal tubes has been shown to be similar to that isolated from specimens obtained by capsule ${ }^{10}$ and by needle aspirations at laparotomy. ${ }^{11}$ The validity of the results on specimens aspirated through long tubes has been further confirmed by work in experimental animals and in humans. ${ }^{12}$ Nevertheless, in our study the transpyloric tubes remained in situ for long periods and qualitative changes in the bacterial flora might have been produced $;^{2}$ our results should therefore, be interpreted with some caution. However, three conclusions are clearly evident. Firstly, the density of growth in the upper gut increased with age as it did in the pharynx, stomach, and faeces; secondly, the predominance of Gram-negative organisms was consistently higher in the upper small intestine than that in the gastric aspirate; and thirdly, in the 3 neonates who, since birth, had been heavily colonised with Gram-negative bacteria, far from the upper small intestine being spared, it was more heavily colonised than the stomach. We suggest that in the very small neonate after the first few days of life there may be a predominantly Gramnegative flora. This is clearly the case in the transpylorically-fed, ill, preterm neonate where qualitatively, the faecal flora reflects the upper intestinal flora. Other contributing factors, apart from the presence of a tube, may be impaired function of the pylorus and deranged gut motility in ill neonates, or decreased gastric acidity which is also characteristic of the very preterm infant.

We were unable to recover significant numbers of anaerobic organisms. This was not owing to any deficiency of technique which was also used to 
study faecal flora in term healthy neonates in whom a luxuriant growth of anaerobic organisms was obtained. The experience of Graham et al. ${ }^{13}$ was similar. They found that in ill low birthweight neonates anaerobic organisms did not achieve the importance found in normal infants.

A significant resident upper intestinal Gramnegative flora could lead to impaired assimilation of feeds. ${ }^{2}$ This has been reported in nasojejunallyfed babies ${ }^{14}$ but other investigators did not substantiate this finding. ${ }^{1516}$ However, the Gramnegative flora could play a contributory role in the previously reported increased incidence of necrotising enterocolitis in these babies. In the present study group, the incidence of necrotising enterocolitis was high for reasons which are not immediately apparent. This group of babies was essentially artificially fed but the use of unheated raw human milk may offer some immunological advantages. ${ }^{17}$ In preterm infants the feeding of raw human milk does not reduce the numbers of coliforms in the faeces, but other factors acting in the gut lumenfor example the anti-adherent effect of secretory $\operatorname{IgA}$ on E. coli-may be due to the beneficial effects of raw human milk. ${ }^{18}$ The very slow, cautious initiation of enteral feeds during the acute illness in these neonates may also be important in preventing the condition.

More studies on the upper gut flora in neonates of very low birthweight are necessary as until now all conclusions and assumptions have been extrapolated from studies on older infants and children under very different conditions from those encountered by the very low birthweight newborn baby.

We thank the microbiology laboratory staff, Children's Hospital, Sheffield, for performing the cultures; the nursing staff of the neonatal intensive care unit, Jessop Hospital for Women, Sheffield, for their co-operation and expert nursing care given to the babies.

This work was supported by a grant from the special trustees of the former United Sheffield Hospitals.

\section{References}

1 Rhea J W, Kilby J O. A nasojejunal tube for infant feeding. Pediatrics 1970; 46: 36-40.

2 Challacombe D N, Richardson J M, Anderson C M. Bacterial microflora of the upper gastrointestinal tract in infants without diarrhoea. Arch Dis Child 1974; 49: 264-9.

3 Boros S J, Reynolds J W. Duodenal perforation: com- plication of neonatal nasojejunal feeding. J Pediatr 1974; 85: $107-8$.

4 Heird W C. Nasojejunal feeding: a commentary. $J$ Pediatr 1974; 85: 111-2.

5 Vasquez C, Arroyos A, Valls I Soler A. Letter: Necrotising enterocolitis. Increased incidence in infants receiving nasoduodenal feeding. Arch Dis Child 1980; 55: 826.

6 Boxall J, Gendle N. Measuring and passing a duodenal/ jejunal feeding tube. Nursing Times 1979 ; 75: 1459-60.

7 Rotimi V O, Duerden B I. The development of the bacterial flora in normal neonates. J Med Microbiol 1981; 14: $51-62$.

8 Anderson C M, Challacombe D N, Richardson J M. The bacterial flora of the upper gastrointestinal tract in children both in health and disease. In: Skinner F A, Carr J G, eds. The normal microbial flora of man. New York: Academic Press, 1974: 197-203.

9 Drasar B S. Some factors associated with geographical variations in the intestinal microflora. In: Skinner F A. Carr J G, eds. The normal microbial flora of man. New York: Academic Press, 1974: 187-96.

10 Kalser M H, Cohen R, Arteaga I, et al. Normal viral and bacterial flora of the human small and large intestine. N Engl J Med 1966; 274: 500-5, 558-63.

11 Anderson C M, Langford R F. Bacterial content of the small intestine of children in health, in coeliac disease, and in fibrocystic disease of the pancreas. $\mathrm{Br} M e d \mathrm{~J} 1958$; i: $803-6$.

12 Gorbach S L, Plaut A G, Nahas L, Weinstein L, Spanknebel G, Levitan R. Studies of intestinal microflora. II. Microorganisms of the small intestine and their relations to oral and fecal flora. Gastroenterology 1967; 53: 856-67.

13 Graham J M, Taylor J, Davies P A. Some aspects of bacterial colonisation in ill, low birthweight, and normal newborns. In: Stern L, Friis-Hansen B, Kildeberg P, eds. Intensive care in the newborn. Paris: Masson, 1976: 59-72.

14 Roy R N, Pollnitz R P, Hamilton J R, Chance G W. Impaired assimilation of nasojejunal feeds in healthy low birth-weight newborn infants. J Pediatr 1977; 90: 431-4.

15 Minoli I, Moro G, Ovadia M F. Nasoduodenal feeding in high risk newborns. Acta Paediatr Scand 1978; 67: 161-8.

16 Milner R D G, Minoli I, Moro G, Rubecz I, Whitfield M F, Assan R. Growth and metabolic and hormonal profiles during transpyloric and nasogastric feeding in preterm infants. Acta Paediatr Scand 1981; 70: $9-13$.

17 Gustafson B, Kjellman B. Use of transpyloric tube feeding with nonpasteurised human milk. J Pediatr 1981 ; 99: 300-2.

18 Gothefors L A, Davies P A. Feeding preterm infants with raw and heat-sterilised human milk: effects on faecal flora. In: Visser H K A, ed. Nutrition and metabolism of the fetus and infant. Fifth Nutricia Symposium. The Hague: Nijhoff, 1979: 285-95.

Correspondence to $\mathrm{Dr} \mathrm{H}$ D Dellagrammaticas, 2nd Department of Paediatrics, University of Athens, Aglaia Kyriakou Children's Hospital, Athens 617, Greece.

Received 15 October 1982 